I Centro Federal de Educação Tecnológica do Rio de Janeiro (Cefet-RJ),

Nova Friburgo, RJ, Brasil

tarcilasformiga@gmail.com

https://orcid.org/oooo-ooor-8937-9296

Tarcila Soares Formiga '

\title{
PROJETOS AFETIVOS E ESTÉTICOS: OS VÍNCULOS ENTRE O CRÍTICO DE ARTE MÁRIO PEDROSA E $O$ ARTISTA ALEXANDER CALDER
}

As relações de amizade podem ser vistas como uma forma de integração dos indivíduos em sociedade, conectando-os no interior de grupos e formando um sistema de interações sociais não baseadas em trocas e relações de utilidade (Silver, I990: I493-I494). Quando se tem em vista a formulação de projetos coletivos - sejam eles políticos, culturais ou artísticos -, os vínculos criados entre indivíduos em interação podem ser considerados os principais fatores explicativos para a produção das ideias que cercam a criação desses projetos (Collins, I998). Os conflitos e as alianças gerados no interior de um sistema de relações marcado por forte densidade social dariam origem a situações de motivação e solidariedade que garantem a coesão de um grupo, além de legitimar os projetos a ele associados. No caso de grupos culturais, conforme analisa Raymond Williams (I982), as ideias e práticas que sustentam as relações de amizade permitem também a formação de grupos sui generis, que, muitas vezes, passam a desfrutar de uma significação cultural e social mais ampla no interior de uma sociedade.

No presente artigo, uma relação de amizade - e suas consequências - vai merecer destaque: aquela estabelecida entre o artista norte-americano Alexander Calder e o crítico de arte Mário Pedrosa. O vínculo entre ambos é fator importante na compreensão tanto do projeto crítico de Pedrosa como também da plataforma artística em que ele desempenhou papel central em sua criação, a saber, o projeto construtivo no Rio de Janeiro. A amizade entre Pedrosa e Calder, que teve início quando o crítico ainda estava vivendo exilado nos Esta- 
dos Unidos, entre I938 e I945, também pode ser compreendida como um aspecto central da reestruturação da sensibilidade pela qual passou Pedrosa e que, de acordo com Bruno Gustavo Muneratto (20 I I: I3), "recondicionou o destino de Pedrosa como crítico de artes plásticas", "quando em contato com aquelas novas possibilidades sensoriais da arte abstrata materializadas nos móbiles do estadunidense Alexander Calder".

O interesse em analisar os desdobramentos do encontro entre um artista e um crítico de arte pode ser explicado dentro de um quadro mais amplo de transformações que se processaram no cenário artístico brasileiro nas décadas de 1940 e I950, quando a ênfase em um projeto artístico marcadamente brasileiro, como aquele vinculado ao modernismo dos anos I920, passou a dar lugar a um debate entre diversas vertentes da arte moderna, com destaque para o

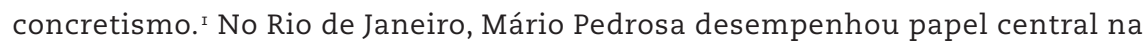
criação de um núcleo de sociabilidade que colocou um grupo de jovens artistas em contato com ideias sobre o fenômeno estético que valorizavam as formas privilegiadas - formas simples, regulares e simétricas capazes de se impor aos sentidos do espectador. Por um lado, sua atuação no ateliê de pintura do Centro Psiquiátrico Nacional Pedro II, juntamente com artistas como Almir Mavignier e Ivan Serpa, e sua defesa da produção artística dos esquizofrênicos teriam, conforme afirma Glaucia Villas Bôas (2008), contribuído para a "conversão" de artistas para o programa concretista. Por outro, as reuniões realizadas em sua casa, onde debatia as ideias que estava discutindo em sua tese Da natureza afetiva da forma na obra de arte, colocaram-no na posição de teórico dos artistas concretos que, no início da década de i950, deram origem ao Grupo Frente. ${ }^{2}$

Este artigo, por sua vez, pretende elucidar outro momento importante para o desenvolvimento de um projeto moderno para as artes plásticas nos anos I940 e I950, que foi o contato de Mário Pedrosa com as obras do artista Alexander Calder e a relação de amizade estabelecida entre eles. O encontro com o artista norte-americano é um dos fatores que ajuda a explicar o interesse de Pedrosa em voltar novamente sua atenção para a crítica de arte, campo de atuação em que ele contribuiu para legitimar as experiências artísticas do projeto concretista. Essa relação, portanto, vai ser compreendida aqui como uma importante etapa de viragem intelectual para o crítico, dando início à construção de um vocabulário na crítica que foi capaz de legitimar as experiências dos artistas concretos brasileiros. Sobre a relação entre os vínculos de amizade e mudanças de trajetória intelectual, Ricardo Benzaquen (20I4: I8I) afirma:

Estamos, como se pode perceber, no mais legítimo terreno do idealismo alemão, marcado pela ideia de Bildung, isto é, de um projeto de formação, de aperfeiçoamento da personalidade que exige a intervenção de algo externo e objetivo que, agindo como se fosse um desafio lançado à vida interior, força a subjetividade a se transformar para enfrentá-lo, fazendo com que, por essa rota, ela termine por alcançar um estágio superior mais cultivado de si mesma. 
Após ter saído do Brasil na condição de exilado, em um contexto de perseguição a militantes de esquerda no período posterior ao golpe de 1937, 3 Pedrosa foi paulatinamente voltando sua atenção para as questões do mundo da arte e para o exercício judicativo. O fato de ter escrito importantes textos sobre arte nesse período e assumido uma coluna de artes plásticas apenas um ano após ter retornado ao Brasil, em I946, corroboram a hipótese de que Pedrosa teria redefinido suas prioridades nesse decurso de tempo, ao se afastar da militância política sem, no entanto, abandonar suas ideias de transformação social que seriam integradas a seu pensamento estético. Ademais, o contexto intelectual dos Estados Unidos nesse momento, com destaque para o surgimento de uma geração de crítico que gravitava em torno da Partisan Review, ${ }^{4}$ e a publicação do Manifesto por uma arte revolucionária independente, lançado em I938, que apresentava as alternativas de Leon Trotski e Andre Breton à instrumentalização da arte imposta na então URSS, teriam causado um grande impacto em Pedrosa e seriam fatores explicativos para sua defesa da arte concreta após seu retorno ao Brasil, juntamente com os contatos estabelecidos com críticos e artistas norte-americanos.

A ênfase na relação de amizade entre Calder e Pedrosa tem o intuito de questionar umas das principais chaves de interpretação da trajetória do crítico, que chama a atenção para a oposição entre suas atividades no campo da política e no campo das artes. Segundo Otília Arantes (I99I: 3I), o ano de I944 teria marcado um processo de "conversão" de Pedrosa para a crítica de artes plásticas - em relação a um período anterior em que teria se dedicado majoritariamente à militância política. A publicação de dois textos sobre Calder nesse ano, de acordo com Arantes, teria colocado questões como autonomia da arte e abstração, arte e utopia na agenda do crítico, que passaria a ser reconhecido, principalmente, por meio de sua atuação no exercício judicativo a partir desse período.

Embora Arantes destaque a importância da publicação dos textos de Calder para uma reaproximação de Pedrosa com o mundo da arte, este trabalho parte de outros pressupostos. Em primeiro lugar, a construção da trajetória de Mário Pedrosa como crítico de arte foi paulatina, datando da década de I920 sua aproximação com intelectuais e artistas oriundos do círculo modernista e seu interesse pelas questões relativas ao fenômeno estético. ${ }^{5} \mathrm{Em}$ segundo lugar, desde a década de I930, quando publicou seus primeiros textos sobres artes plásticas, o crítico já demonstrava interesse em relacionar as atividades nesse campo com as arenas social e política. Nos anos I940, todavia, Pedrosa reformulou suas posições acerca da relação entre as atividades artísticas e a política, atribuindo à arte a tarefa de criar um ambiente social modificado por novas formas de percepção e de sensibilidade. Sua experiência no exílio, portanto, com destaque para a relação do crítico com Calder, foi fundamental para que o crítico desenvolvesse suas ideias acerca do fenômeno estético, superando 
uma forma mecânica de tratar a relação entre arte e política e a dicotomia entre militância e atuação intelectual. Segundo Marcelo Vasconcelos (201 2: 62), "foi nos Estados Unidos que Pedrosa foi apresentado a novas possibilidades de militância política que não apenas ultrapassavam o bolchevismo como também ultrapassavam os limites da política stricto sensu".

Além de presenciar os debates entre arte e política, realismo e abstração, conduzidos por intelectuais nova-yorkinos a partir do final na década de I930, foi também durante o exílio que Pedrosa estabeleceu amizade com o artista Alexander Calder. Uma hipótese deste trabalho é que foi por meio do contato com o artista que o crítico teve a oportunidade de construir um novo vocabulário para tratar dos objetos artísticos, colocando na agenda do dia a discussão sobre o abstracionismo, a relação entre a arte e vida e entre arte e política. A relação de amizade de Calder e Pedrosa, portanto, vai ser compreendida por meio da existência de valores em comum que uniam o artista e o crítico. Foi na relação com Calder e seu trabalho que Pedrosa conseguiu encontrar uma solução para conciliar a defesa do abstracionismo com um posicionamento político que pressupunha uma relação entre fenômeno artístico e práxis, isto é, a integração da arte na vida cotidiana, transformando-a.

Na primeira parte deste artigo, os desdobramentos dessa relação serão vistos por meio de dois textos publicados por Pedrosa em I944, no jornal Correio da Manhã, que serão analisados com o intuito de observar como o crítico foi, paulatinamente, forjando um instrumental para a análise estética que não condicionava a relação entre a arte e as esferas social e política com a existência de uma mensagem de conteúdo social explícito nos objetos artísticos, e que não estava pautada no repertório realismo/naturalismo, como era comum nos críticos associados ao modernismo da década de I920. Já na segunda parte, a realização em I948 de uma exposição de Calder no Rio de Janeiro, com a ajuda de Mário Pedrosa, e um artigo escrito pelo crítico no mesmo ano vão ser destacados como aspectos cruciais na amizade entre o crítico e o artista, marcando, por um lado, a aproximação de Calder com o Brasil, por meio de sua inserção em redes culturais e artística no país, e, por outro, uma defesa mais explícita do abstracionismo por parte de Pedrosa, que passaria a defender o papel político da arte de vanguarda, associando o movimento abstracionista a uma reorganização da ordem social em termos "racionais, harmônicos e científicos". ${ }^{6}$

Por fim, cabe destacar que este trabalho faz parte de um conjunto mais amplo de pesquisas que são realizadas no Núcleo de Pesquisa em Sociologia da Cultura (Nusc), no Instituto de Filosofia e Ciências Sociais da UFRJ, sob a coordenação da professora Glaucia Kruse Villas Bôas. ${ }^{7}$ Os vínculos entre arte e vida social, a análise do modernismo nas artes e o papel de instituições, críticos e outros agentes na legitimação de práticas artísticas são alguns dos temas privilegiados pelos pesquisadores organizados em torno desse grupo. Dentro desse quadro mais amplo de trabalhos que têm o objetivo de analisar as práti- 
cas e narrativas que engendram as regras de funcionamento do campo artístico brasileiro, este artigo visa compreender como os vínculos entre certos atores sociais contribuem sobremaneira para uma transformação dos discursos associados aos objetos artísticos, assim como para uma mudança nas experiências estéticas consideradas legítimas.

\section{MÁRIO PEDROSA E A DEFESA DA ABSTRAÇÃO NAS OBRAS DE ALEXANDER CALDER}

Alexander Calder e Mário Pedrosa conheceram-se em I944, após Pedrosa ter visitado sua exposição individual no Museu de Arte Moderna de Nova York (MoMA). Essa mostra foi a primeira grande retrospectiva das obras de Calder, reunindo desde seus primeiros trabalhos até aqueles mais recentes. Após a oportunidade de ver uma exposição com um panorama do trabalho do artista, o crítico o encontrou em seu ateliê. Em sua autobiografia, o escultor confirma essa informação, mencionando como teria começado sua amizade com Pedrosa: "Nós nos conhecemos em Nova York, em I944. Ele veio me procurar, e nos tornamos grandes amigos" (Calder, I977: 20I). ${ }^{8}$

Nesse encontro, Pedrosa, de acordo com sua esposa, Mary Houston Pedrosa (I980), fez diversas anotações durante a conversa com o artista, tomando notas para futuros trabalhos, e foi presenteado com uma escultura. O impacto dessa conversa e da visita à exposição pode ser visto nos dois artigos que o crítico escreveu sobre o artista e que foram publicados em I 944 no jornal Correio da Manhã. Nos textos "Calder, escultor de cataventos" e "Tensão e coesão na obra de Calder", Pedrosa realizou um estudo profundo da obra do artista, além de ter desenvolvido ideias que passaram a fazer parte não apenas de seu pensamento crítico dali por diante, mas também do projeto que ele previa para a arte moderna.

No primeiro artigo, Pedrosa enfatiza a questão principal que parece ter chamado sua atenção para o trabalho de Calder: a harmonia entre o plástico e o funcional. Se essa harmonia ainda não estava presente em suas primeiras obras com arame, o crítico afirma que, ainda assim, o artista já teria atingido nesse momento um "valor plástico mais estruturado", principalmente por meio da sugestão do volume:

Mas por outro lado, com sua atração irresistível pelo mundo das formas abstratas puras - esse andaime de formas virtuais constituindo como que a própria estrutura abstrata do universo, e que revela no artista que a sente um traço indelével de classicismo - Calder é o oposto dos artistas chineses. Padece desse perene encantamento formal puro, desconhecido daqueles artistas embebidos de subjetivismo, mas tão assinalado nas grandes manifestações da arte ocidental (Pedrosa, 2000: 57).

Esse fragmento merece destaque por conta do vocabulário utilizado pelo crítico para fazer referência ao trabalho do escultor. Além do já citado "valor 
plástico mais estruturado", Pedrosa ainda menciona aquelas que seriam "formas abstratas puras" e uma "estrutura abstrata do universo". Mais adiante, quando descreve um divisor de águas na trajetória do artista - seu encontro com o trabalho de Piet Mondrian -, Pedrosa ressalta que um mundo novo se abriu para o artista, isto é, aquele da "pura forma abstrata".

Na utilização desses termos, nota-se a ênfase que o crítico dá à expressão formal do artista, em detrimento da representação do conteúdo na obra de arte. Não é à toa que ele destaca que, após o contato com Mondrian, Calder teria abandonado a preocupação com o assunto, com a representação, como quando começou suas experiências com o arame. A partir desse momento-chave, Pedrosa afirma que o escultor se teria tornado um artista abstrato: "Da representação direta ou sugestiva, ele passa ao campo da composição abstrata. É uma fase decisiva na curva da arte de Calder. A partir de então, foi enfileirado entre os abstracionistas" (Pedrosa, 2000: 58).

Em vez da improvisação e do humor que marcavam suas figuras do circo, quando ainda estava começando sua carreira artística na década de I920, Pedrosa ressalta uma virada no trabalho do artista, que iria privilegiar formas mais simples, figuras geométricas, como "esferas, esferoides, círculos e discos", e utilizar cores primárias. É dessa nova fase, da valorização dos elementos plásticos em detrimento do assunto, que teriam surgido as "esculturas abstratas, estáveis e imóveis", que, de acordo com Pedrosa, o artista Hans Arp teria denominado "estábiles".

Após essa experiência com as esculturas abstratas imóveis, os "estábiles", Calder passou a incorporar o movimento em seus trabalhos, dando origem aos "móbiles":

\begin{abstract}
O problema fundamental dos móbiles, essa busca das relações espaciais dos objetos, equivale quase à procura metafísica da realidade não contingencial das coisas. A essencialidade das formas desencarnadas de qualquer convenção, ou função eterna. Para mover-se nesse mundo das formas puras mais facilmente, recorre a sugestões e motivos não orgânicos. Assim, evita qualquer sugestão naturalista ou realista e mais facilmente achará o material com que construir aquele próprio mundo, em que só o movimento cósmico, o movimento em abstrato, é senhor absoluto (Pedrosa, 2000: 6I).
\end{abstract}

Pedrosa lança luz para o abstracionismo presente nas obras do artista, isto é, as "formas desencarnadas" denominadas "móbiles", enfatizando que elas se distanciam de qualquer representação do mundo exterior. Ao destacar a importância dessas formas abstratas nas esculturas do artista, o crítico estaria antecipando o privilégio que iria conferir à arte abstrata posteriormente, quando se tem em vista, por exemplo, a tese que escreve no final da década de I940, intitulada "Da natureza afetiva da forma na obra de arte". Nessa tese, ele afirma que as propriedades formais de um objeto possuiriam, por si mesmas, um sentido, uma fisionomia moral, que independe das experiências anteriores dos sujeitos que contemplam esses objetos (Pedrosa, I979: 68). 
O texto "Calder, escultor de cataventos" pode ser contextualizado, portanto, da seguinte maneira: em primeiro lugar, ele deve ser localizado no interior dos debates com os quais Pedrosa teve contato nos Estados Unidos, notadamente aqueles que diziam respeito à arte abstrata, que, desde a década de I930, já era objeto de discussão de intelectuais como Meyer Schapiro e Clement Greenberg;" em segundo lugar, esse texto e também "Tensão e coesão na obra de Calder" evidenciam a formulação de questões que vão aparecer com mais ênfase nos trabalhos posteriores de Pedrosa, especialmente, aqueles escritos após sua tese, em que a defesa das "formas privilegiadas" na arte vai assumir um papel central em suas análises sobre o objeto artístico.

$\mathrm{Na}$ discussão sobre a abstração na arte, todavia, Pedrosa enfatiza um elemento importante para além da valorização das formas puras e desencarnadas. A escolha de Calder para dar início a esse debate pode ser explicada, entre outros aspectos, pelo fato de o artista unir purismo e humor em seus trabalhos. Se o pontapé para que o artista evitasse a sugestão naturalista veio com a obra de Mondrain, o contato com os trabalhos de Miró o colocou em relação novamente com o humor, que já estava presente no início de sua carreira artística. Sobre a influência do pintor catalão nas esculturas de Calder, o crítico afirma: "E então, só então, recobrava, graças a Deus, o humor, quase recalcado no ambiente depurado, quase místico, do abstracionismo. Seu humor casava-se perfeitamente com a alegria gritante da pintura de Miró" (Pedrosa, 2000: 6I-62).

A junção de humor e formas puras é um elemento importante do trabalho de Calder, segundo Pedrosa. Seria esse primeiro elemento incorporado aos trabalhos do escultor que garantiu sua proximidade com a vida, entendida a partir de dois aspectos: de um lado, seus trabalhos seriam desprovidos do "não me toques" característico da maioria dos objetos artísticos modernos; de outro, o humor em sua arte o aproximaria do grande público. No contato com o trabalho de Calder, portanto, Pedrosa defendeu uma concepção sobre o fenômeno estético que pressupõe uma integração da arte na vida cotidiana:

Essa é uma arte, pois, que não se separa da vida, e, se acontece, também não se recusa a servir a outra, tende a impregnar com sua sedução o ambiente da vida moderna; e resiste, galharda, aos iluminados espaços ao ar livre, nos livrando das estátuas indefectíveis das praças e jardins públicos, de homens a cavalo, ou de barba e espada, quando não de fraque ou camisolão. Mas pode povoar essas praças e esses jardins de coisas nunca vistas, de sugestões de mundos e bichos desconhecidos, de fábulas novas, de sonhos, de imaginações e silêncios revificantes... que se mistura, para dar realce e beleza às atividades industriais da vida moderna [...] E sua bonomia é tanta, e também sua virtualidade plástica, que pode condescender, sem que isso se degrade, mas antes na vida cotidiana se integre para purificá-la do vulgar e do feito, a servir até de distintivo para estabelecimentos comerciais (Pedrosa, 2000: 65). 
Em outro texto também publicado em I944, "Tensão e coesão na obra de Calder", Pedrosa reforça novamente a relação que o escultor estabeleceu entre a "vida e a abstração". Além de retomar a discussão sobre os "estábiles" e "móbiles" do artista, o crítico também aproveita para reafirmar que, além da unidade formal que seus trabalhos apresentavam, ele conseguiu agregar o sonho, a fantasia e a imaginação. Cabe ainda destacar que a ênfase nessa unidade é discutida juntamente com a noção de "funcionalidade", que é mobilizada nesse artigo não para vincular seus trabalhos a uma realidade que lhe é exterior, mas a fim de ressaltar a força sugestiva que seus trabalhos apresentam: "A arte de Calder só conhece uma funcionalidade - a do próprio material em que trabalha, a que é vital, inerente à matéria. E mais nenhuma externa ou estranha à intrínseca propriedade desta" (Pedrosa, 2000: 78).

Mesmo sem nenhuma função prática, a sugestão oriunda das formas desencarnadas nos trabalhos do artista, unidas à fantasia, já o teria colocado em outro patamar, segundo Pedrosa, uma vez que Calder conseguiu juntar o purismo do construtivismo com a poética do surrealismo, desrespeitando os cânones artísticos até então estabelecidos. Desse modo, o escultor escaparia tanto do distanciamento da arte em relação à práxis vital quanto de um subjetivismo desprovido de expressão formal:

Casando a vida e a abstração, conjugando o humor à mecânica, ele navega entre as duas grandes alas da arte moderna: o surrealismo, com seu romantismo incurável que degenera às vezes em charada anedótica, e o abstracionismo cuja obsessão do purismo formal se revolve não raro entre uma espécie de misticismo branco e a pura puerilidade" (Pedrosa, 2000: 79).

O trabalho de Calder, portanto, foi uma espécie de acerto de contas com os dilemas que Pedrosa enfrentava desde suas primeiras análises sobre artes plásticas, principalmente aquelas em que tratou dos trabalhos de Candido Portinari, quando oscilava entre as preocupações com os elementos plásticos das obras e sua relação com o meio circundante. Ao se deter nos trabalhos do escultor, o crítico concluiu que a "funcionalidade" dos objetos artísticos não deve ser encontrada em uma relação direta entre eles e a realidade exterior, mas na influência que esses objetos podem ter na transformação da sensibilidade dos homens, argumento que ele vai aprofundar alguns anos mais tarde em sua tese, conjugando experimentação no campo estético com transformação social. ${ }^{10}$

Os dois textos sobre Alexander Calder escritos por Pedrosa em I944 chamam a atenção, portanto, para o papel que a relação com o artista desempenhou em sua trajetória intelectual. Segundo Francisco Ortega (2009: 83), os laços de amizade surgem como uma alternativa ao engessamento das relações mais institucionalizadas, abrindo o espaço para que os indivíduos sejam "arquitetos de uma rede" construída por eles mesmos. Nesse sentido, a amizade abriria espaço para o novo, para a experimentação, sendo, portanto, "instável e dinâ- 
mica em relação a valores". O interesse de Pedrosa em se dedicar à crítica de arte com mais afinco, especialmente após o retorno do exílio, e sua defesa da abstração como um projeto intelectual, são entendidos aqui como desdobramento dessa relação criada entre crítico e artista.

A proximidade entre Calder e Pedrosa fica evidente não apenas nos textos - o crítico escreveu artigos esparsos sobre o artista durante um período de 30 anos -, mas também no fato de o vínculo entre eles ter-se mantido mesmo com o retorno de Pedrosa ao Brasil em I945. ${ }^{\text {II }}$ A permanência dessa relação pode ser vista, por exemplo, nos esforços que o crítico empreendeu para organizar uma mostra individual do artista, que aconteceu em I948, em São Paulo e no Rio de Janeiro. Os laços de amizade que uniam ambos, portanto, foram alimentados durante um longo decurso de tempo, em que a influência mútua entre crítico e artista assumiu um aspecto central, principalmente no caso de Pedrosa, para quem o escultor se tornou uma espécie de referência para projetos no exercício judicativo.

\section{ALEXANDER CALDER NO BRASIL E A DIMENSÃO UTÓPICA DA ARTE}

Em I948, Alexander Calder aportou no Brasil com o objetivo de participar de sua primeira mostra individual no país, que seria realizada em duas cidades: Rio de Janeiro e São Paulo. Em sua autobiografia Calder destaca essa passagem pelo país, dando destaque às amizades construídas no campo artístico e cultural brasileiro. A iniciativa de organizar a mostra, por exemplo, teria partido, segundo o artista, especialmente do arquiteto Henrique Mindlin, conforme é possível ver nesse trecho: "Mindlin era um entusiasta do meu trabalho e disse que eu deveria ir ao Brasil. Então, quatro anos depois, em I948, tendo enviado vários trabalhos para Henrique no Rio, Louisa e eu fomos para o Brasil, mas fizemos desvios na rota" (Calder, I977: I99). ${ }^{\text {I2 }}$

Por ocasião de suas mostras, Calder aproveitou para fazer viagens ao Brasil, passando brevemente pelas cidades de Salvador e Ouro Preto. Em sua autobiografia, o artista relata também ter atravessado o rio Amazonas, além de ter visitado a cidade de Belém. Em São Paulo, Calder frequentou exposições de artistas brasileiros, como a de Cícero Dias no prédio provisório do MAM paulista, e visitou Flávio de Carvalho em sua fazenda próxima a Campinas. Após deixar essa cidade, ele retornou ao Rio de Janeiro, onde instalou uma oficina para trabalhar com ajuda da arquiteta Lota de Macedo Soares, lá ficando aproximadamente duas semanas.

Em uma passagem de sua autobiografia, Calder relata a estada no Brasil, especialmente o período que passou no Rio de Janeiro. Além de trabalhar na casa arranjada por Lota de Macedo Soares, o artista também pôde aproveitar o convívio com seus amigos brasileiros em festas realizadas em lugares como o Copacabana Palace, animadas por rodas de samba e cachaça. Em sua festa de despedida, Calder relata que seu amigo Heitor dos Prazeres, cantor e pintor, levou seu grupo de música para tocar no evento. Já em outro trecho, ele narra 
sua ida a um terreiro, que foi fotografada e publicada na revista Fon-Fon, causando escândalo na época: "Certa noite, fomos a uma macumba, em algum lugar no interior do Rio. Havia mulheres de branco dançando num grande círculo. Nós entramos no círculo também. Eu dancei com uma mulher de cor. Algum fotógrafo russo tirou uma foto nossa e publicou na Fon Fon, uma revista escandalosa do Rio" (Calder, I977: 203). ${ }^{\text {13 }}$

Se essa estada no Rio de Janeiro teve impacto em Calder, que narrou a passagem por essa cidade em sua autobiografia, ela também foi considerada um divisor de águas para Pedrosa, que incluiu a exposição do artista entre os principais marcos do desenvolvimento artístico do país no período anterior à realização das bienais. Alguns fatores indicam a importância da mostra. Em primeiro lugar, ela ocorreu em um prédio ícone da arquitetura brasileira, o edifício do Ministério da Educação, projetado por uma equipe que contava com nomes como Oscar Niemeyer e Lúcio Costa, sob a consultoria do arquiteto franco-suíço Le Corbusier. ${ }^{\mathrm{I}}{ }^{4} \mathrm{Em}$ segundo lugar, a montagem da exposição carioca contou com importantes expoentes do cenário artístico brasileiro, como Pedrosa, Mindlin, Niemeyer e Roberto Burle Max. Além disso, cabe destacar a recepção da imprensa. Carlos Drummond de Andrade, Pietro Maria Bardi, Sergio Milliet, Pedrosa e Mindlin manifestaram-se publicamente a respeito da exposição, fazendo críticas elogiosas à mostra.

Coube a Pedrosa fazer um pronunciamento na inauguração, intitulado "Calder a música dos ritmos visuais", em que faria um resumo dos dois artigos que havia escrito sobre o artista ainda em I944. Em sua autobiografia, Calder narra a experiência de participar da inauguração da mostra, naquela que seria sua primeira visita ao país, ${ }^{15}$ e também suas impressões sobre a situação que cercou o pronunciamento do crítico: "Sentei-me na primeira fileira para ouvi-lo melhor, mas, como era tudo em português, cochilei. A certa altura, a imprensa quis tirar uma foto, e me acordaram para isso. Mas como Mário estava no canto oposto do palco, todos os olhos estavam voltados para ele, exceto os meus, que olhavam diretamente para a câmera" (Calder, I977: 20I). ${ }^{\mathrm{I}}$

Cabe observar que, embora Pedrosa tivesse destacado a importância da mostra para o desenvolvimento do cenário artístico brasileiro, Calder parece não ter dado importância à exposição e ao impacto que ela causou nos críticos e artistas do Brasil. ${ }^{17}$ Isso chama a atenção, por um lado, para a existência de uma relação de desigualdade presente na amizade entre Calder e Pedrosa, visto que o primeiro parece ter tido uma importância maior para as mudanças na trajetória intelectual de Pedrosa, sendo o impacto da amizade entre ambos pouco visível na carreira do artista; ${ }^{18}$ por outro lado, para Calder, a realização dessa exposição parecia significar uma oportunidade para conviver por alguns dias com seus amigos brasileiros, estreitando esses vínculos de amizade.

Essa exposição também deve ser entendida em um contexto de transformações que se processavam no meio artístico brasileiro. Vários fatores re- 
lacionados a essa mostra podem ser enumerados para ilustrar essas mudanças. Nesse período, os debates em torno das diversas tendências no interior da arte moderna, como aquelas ligadas ao realismo pictórico e ao abstracionismo, estavam no ápice, haja vista a disputa de diversos críticos e artistas defensores dessas correntes. Cabe destacar, por exemplo, que um ano após essa mostra individual de Calder, inaugurou-se o MAM paulista com uma exposição intitulada Do figurativismo ao abstracionismo, que, apesar do nome, apresentava em sua maioria artistas ligados à tendência abstrata. ${ }^{19}$ Nesse contexto, porém, a arte abstrata sofria críticas por parte de um grupo de críticos, como aqueles que atuavam na Fundamentos: revista de cultura moderna, plataforma de defesa do realismo socialista. Pedrosa, por sua vez, além de trabalhar para o desenvolvimento do concretismo no Rio de Janeiro, ainda se manifestou de forma favorável a seus representantes em textos de jornal e catálogo, e em debates com outros críticos.

A exposição de Calder teria papel de destaque nesse contexto, como o próprio Pedrosa procurou demonstrar ao enfatizar a mostra do artista realizada no Rio de Janeiro, bem como a do artista suíço Max Bill - um dos principais expoentes do concretismo em âmbito internacional -, em I950, no Museu de Arte de São Paulo. No artigo "Às vésperas da Bienal”, Pedrosa quis evidenciar os acontecimentos artísticos que precederam a exposição de Max Bill e que haviam desempenhado o papel de revelar novas tendências na arte no meio artístico brasileiro. Sobre Calder, ele afirma: "A mostra dele no Rio exibia um grande artista, sui generis, que, pela própria maneira jovial e original com que se apresentava em pessoa e na obra, parecia a muitos espíritos da Europa e daqui também, e dos mais avisados, como não se enquadrando na concepção que tinham da escultura" (Pedrosa, 2007: 282).

O papel de Pedrosa na divulgação da obra do artista não se esgotou na organização dessa mostra nem, retrospectivamente, quando avaliou seu impacto no meio artístico brasileiro antes das bienais. Em I948, o crítico ainda escreveu outro texto, intitulado "A máquina, Calder, Léger e outros", que se destaca dos artigos anteriores que ele publicou sobre o artista por diversos aspectos. Desses aspectos, chama atenção a ênfase dada pelo crítico à proximidade do trabalho de Calder com a produção industrial e sua relação com o desenvolvimento técnico da sociedade moderna.

Comparando esse texto de I948 com os dois publicados em I944, cabe destacar que o primeiro chama a atenção por mostrar a maturação das ideias que haviam sido apresentadas, principalmente aquelas que dizem respeito à importância das atividades artísticas para a transformação da sociedade e o papel de um artista como Calder na integração da arte com a vida cotidiana. Ademais, o artigo de 1948 evidencia um crítico defensor das experiências artísticas no campo da abstração não apenas associando Calder a essa tendência, mas também demonstrando a influência dessa tendência sobre o artista. $O$ 
abstracionismo, para Pedrosa, é o ponto para o qual convergem as experiências estéticas e a própria possibilidade de junção entre arte e vida: "Essa marcha do natural para o abstrato formal é uma constante de nossa civilização, marca um dos traços profundos da cultura moderna. Graças a ela, pôde a arte de nossos dias influenciar, como talvez só a arte da renascença o conseguiu, a produção industrial do seu tempo" (Pedrosa, 2000: 83).

Com efeito, a discussão dos trabalhos de Calder contribuiu para que Pedrosa forjasse os argumentos que utilizaria dali por diante em sua defesa da abstração. Nos artigos de I944, essa defesa ainda não era explícita, embora Pedrosa fizesse referência a uma unidade formal nos trabalhos do escultor, mencionasse a influência do "purismo" do construtivismo em suas obras, e posicionasse Calder no rol dos artistas abstratos. Já no texto de I948, Calder não aparece apenas como um artista-referência para o crítico; é considerado "o mais fiel dos construtivistas". A tendência da qual ele seria um representante figura, para Pedrosa, como a maior expressão no mundo das artes, aquilo que ele chama de "cultura moderna".

Outro argumento que pode ser mobilizado para destacar a importância que Pedrosa conferia a um artista como Calder e à arte abstrata pode ser visto na forma como o crítico descreve os movimentos vanguardistas europeus do século XX, como o dadaísmo e o surrealismo. Ao contrário dos artistas desses movimentos, o escultor conseguiu encontrar soluções artísticas para os problemas enfrentados pela sociedade moderna - como o desenvolvimento industrial acelerado - que deram origem a um dos "duendes mais temíveis": a máquina. Em vez do desespero e do otimismo, meios pelos quais os artistas vanguardistas encararam "a máquina", a arte de Calder brotou da relação com a produção industrial, e o escultor buscou na forma como essa produção afeta os indivíduos inspiração para seu processo criativo, ao mesmo tempo em que a transcendia:

Calder não representa, nem abstrai, nem "estiliza a máquina. Nenhuma de suas estruturas é constituída de formas e volumes puramente geométricos, apresentados analiticamente. Seus desenhos e composições são formas puras, convergindo para um todo orgânico. Seus objetos já são máquinas também, mas... de poesia e improvisações. Seus estábiles ou móbiles criam relações fantasiosas, arbitrárias, não mecanizadas. Dessas construções geométricas saem, por vezes, monstros ou animais dir-se-ia pré-históricos, vegetais contemplativos ou tímidos, insetos inéditos, irônicos, de ar diabólico. Mas tudo com vida, e tendo em si mesmo a sua realização e finalidade (Pedrosa, 2000: 85).

Além de evidenciar o relacionamento de Calder com a produção industrial moderna - expressa na imagem da "máquina" -, Pedrosa reforça novamente as "formas puras" e as "construções geométricas" no trabalho do artista, que dão origem a seus "móbiles" e "estábiles"; e a presença do movimento em suas obras, que estaria, porém, a serviço das "relações formais e cores". Na utilização dessas expressões, o crítico reforça um vocabulário que ficaria evidente em 
seus textos posteriores, à medida que passa a trabalhar na construção de um projeto moderno associado ao construtivismo. Se esse projeto passa a se configurar com mais clareza na década de I950, quando contribui para a formação um grupo de artistas no Rio de Janeiro, dando origem a um grupo concretista nessa cidade, foi por meio da relação com Calder e com suas obras que Pedrosa conseguiu enxergar soluções para os problemas que ele vinha tratando em seus textos sobre artes plásticas, como a relação entre arte e vida, forma e conteúdo, objetividade e subjetividade na criação artística.

Foi também nesse artigo sobre o artista que Pedrosa fez referência a um "devenir pictórico", isto é, uma arte como utopia, como projeto para o futuro, que teria o papel de transformar a sociedade e, não, de representá-la. Em textos posteriores, sobretudo aqueles que ele escreveu sobre a arquitetura na década de I950, o crítico iria desenvolver de forma mais explícita o argumento de que as atividades artísticas teriam o papel de antecipar transformações futuras, no âmbito social e político, entrando em conflito, muitas vezes, com o estado de coisas de onde elas surgem. A importância que o crítico atribuía ao fenômeno estético, portanto, estaria ligada a seu potencial transformador, quando ele se imiscui na vida e no cotidiano dos homens, o que lhe garante uma dimensão utópica, as pecto que estaria presente, de acordo com Pedrosa, em um artista como Calder:

Esta arte calderiana não reflete sociedades, nem sublima pesadelos subjetivos. É antes uma porta para o futuro. É já atitude de quem, desprezando o dia presente, sombrio como nos pareça, divisa, de onde está, os horizontes longínquos da utopia, da utopia que eternamente está a esboçar diante de nós. Não é, todavia, um veículo para o artista escapar-se espiritualmente, para com ele isolar-se na sociedade, sem contato vital com esta, todo entregue à expressão de seu próprio extremado e hermético subjetivismo, desesperançado de comunicabilidade. Comunicar-se, ele se comunica quando mais não seja com os homens das futuras gerações, pois estes talvez tenham, enfim, energia bastante para o necessário esforço de integrar a arte à própria vida (Pedrosa, 2000: 90).

Pedrosa apresenta de forma breve sua concepção acerca do fenômeno artístico, afirmando que ele não deveria representar a sociedade presente, mas vislumbrar os caminhos do futuro, daí seu caráter utópico. Além disso, ao se contrapor a essa imagem da arte como um mero reflexo, ele respondia aos comentários sobre a tendência abstrata, quando outros críticos diziam que ela estava distante dos homens e da sua luta, isto é, do ambiente social de onde surgira. A relação da arte com a vida, conforme fala Pedrosa, não se manifesta de maneira explícita, como um reflexo da sociedade. Essa ideia foi desenvolvida posteriormente pelo crítico, quando ele enfatizou que, ao contrário dessa imagem, a arte deveria ser considerada ao mesmo tempo "um fator autônomo e determinante na sociedade e no mundo". ${ }^{\circ}$

A defesa da autonomia da arte frente a seus referentes externos, sem o prejuízo de sua "funcionalidade" - posto que ela seria capaz de transformar o mundo e a percepção dos homens - passa a figurar no repertório crítico de Pe- 
drosa a partir da década de I940, sendo a reflexão em torno da produção de Calder um fator central para a valorização dessa e de outras questões que se tornariam recorrentes em sua atuação no exercício judicativo. O projeto artístico no qual Pedrosa esteve engajado nesse período, sendo considerado um de seus principais teóricos - o movimento concretista carioca - tem relação justamente com um cabedal teórico adquirido pelo crítico, com destaque para os ensinamentos da Gestalt, ${ }^{21}$ e o capital social e cultural adquirido no exílio. No presente trabalho, o momento em que viveu como exilado proporcionou, entre outras experiências, um ponto de viragem na reflexão do crítico sobre o fenômeno estético que é, em parte, devedor do contato com as obras de Calder. A relação estreita entre ambos, crítico e artista, permitiu ainda que essa reflexão maturasse ao longo do tempo, tendo consequências marcantes no meio artístico brasileiro, tanto na forma de projetos artísticos, quanto em projetos no campo da crítica. A defesa da abstração e da autonomia da arte por parte de Pedrosa encontrou sua justificativa, em um primeiro momento, no escultor norte-americano, alçado à condição de amigo e de artista emblemático para o crítico.

\section{CONSIDERAÇÕES FINAIS}

Ao mesmo tempo em que auxiliou no desenvolvimento da plataforma artística concretista, Pedrosa começou a forjar um novo repertório na sua produção crítica, mobilizando-a nas suas reflexões sobre arte. A sua relação com Calder desempenhou um papel importante no que está sendo chamado aqui de "reestruturação da sensibilidade" a qual o crítico teria se submetido e que lhe permitiu destacar as seguintes questões: a valorização da autonomia da arte, da comunicação da obra a partir de seus aspectos fisionômicos, dos vínculos entre arte e vida; e a relação entre mudanças na percepção no contato com os objetos artísticos modernos.

Se para Pedrosa a arte moderna teria o papel de alterar a percepção dos homens, não se pode deixar de notar que ele mesmo, no contato com os trabalhos de Calder, reconfigurou seu arsenal crítico, além de ter se dedicado com mais intensidade à atuação no exercício judicativo após o encontro com o artista e o início da relação de amizade entre ambos. Embora o empenho nessa atividade, que se acentuou especialmente após seu retorno ao Brasil em I945, não possa ser atribuído apenas à amizade do crítico com o escultor, não é possível desprezar o impacto dessa relação para o projeto pictórico concretista no qual Pedrosa trabalhou, e que teve um impacto significativo no meio artístico brasileiro a partir da década de I950. Além do papel de instituições modernas na legitimação de movimentos artísticos como o concretismo - com destaque para os museus de arte moderna no Rio de Janeiro e São Paulo e as Bienais deve-se enfatizar também os vínculos criados entre diversos atores no meio artístico, como é o caso de artistas e críticos, que, muitas vezes, influenciando-se mutuamente, engendram um "devenir pictórico". No caso de Pedrosa, seja re- 
fletindo sobre a obra de um artista ao mesmo tempo em que construía um arcabouço teórico capaz de justificar a presença da arte concreta no Brasil, seja divulgando a obra de um escultor estrangeiro que acabou por reverberar nas experiências estéticas desenvolvidas no país a partir dos anos I950, o encontro com Calder fez deste um artista-referência para o crítico e um ponto de inflexão na sua trajetória como produtor de discursos sobre arte.

Recebido em 5/4/2018 | Aprovado em I/6/2018

Tarcila Soares Formiga é doutora em sociologia pelo Programa de Pós-Graduação em Sociologia e Antropologia da UFRJ e professora do Centro Federal de Educação Tecnológica Celso Suckow da Fonseca (Cefet/RJ), unidade Nova Friburgo. Atua nas áreas de sociologia da cultura e da arte, pesquisando principalmente os seguintes temas: arte, galerias e crítica de arte. 


\section{NOTAS}

I “A experiência concretista estabeleceu a concorrência entre dois programas estéticos. Em contraste com o primeiro programa, que adotou o figurativismo de viés expressionista e cubista com o objetivo de representar a nação brasileira, os artistas concretos se dedicaram à busca de 'formas privilegiadas', que, para alguns, a exemplo de Almir Mavignier, significava liberdade de expressão. Libertar-se da imitação da natureza e deixar de procurar a brasilidade a cada passo, atribuindo à arte um caráter universal, passou a ser o ideal almejado por muitos daqueles que transitavam nos circuitos das artes plásticas" (Villas Bôas, 2014: 270).

2 Sobre a trajetória do grupo concretista carioca, ver Sabrina Santa'Anna (2004).

3 Ver Dainis Karepovs (200I).

4 Essa revista foi criada em I934 pelos editores Philip Rahve William Philips, reunindo, principalmente, intelectuais próximos ao partido comunista nos Estados Unidos. Em 1936, essa publicação foi suspensa como uma resposta dos intelectuais ligados à revista a diversos acontecimentos vinculados às esferas da arte e da política. No que concerne às artes, o questionamento da qualidade de uma literatura dita "proletária" e a desconfiança em relação a uma arte de teor nacionalista concorreu para a mudança do posicionamento dos membros da revista. Em I937, a mudança de posicionamento dos intelectuais da Partisan fica evidente após o retorno da publicação. Além da mudança dos editores, a linha da revista sofreu alterações. Em primeiro lugar, a defesa de uma "literatura proletária" foi abandonada para dar lugar à seguinte posição: a literatura moderna deveria ser livre de todas as interferências políticas.

5 O processo de reconhecimento de Pedrosa no exercício judicativo, em um período que vai da década de I920 até meados da década de I950, foi o objetivo de minha tese de doutoramento intitulada À espera da hora plástica: o percurso de Mário Pedrosa na crítica de arte brasileira (Formiga, 2014).

6 Pedrosa, Mário. A Bienal de São Paulo e os comunistas. Correio da Manhã, Rio de Janeiro, 8/9/I95I. 
7 Alguns dos trabalhos desenvolvidos por pesquisadores do Nusc foram organizados pela professora Glaucia Villas Bôas (20I6) no livro Um vermelho não é um vermelho: estudos sociológicos sobre as artes visuais.

8 No original: "We had met in New York, in I944. He had looked me up and we had become very good friends".

9 Em Nova York, Pedrosa presenciou discussões em torno do realismo pictórico e da abstração, em que um grupo de intelectuais já se posicionava a favor do abstracionismo, buscando justificativas históricas e sociais para explicar sua predominância naquele contexto. Em I937, Meyer Schapiro publicou o texto "Nature of abstract art", na revista Marxist Quaterly. Nele, Schapiro critica a relação mecânica entre arte e política, identificada por ele no realismo socialista, ao mesmo tempo em que defende a arte abstrata de seus detratores, afirmando que ela não estava presa em uma torre de marfim, pois mesmo um artista quando distorce as formas naturais estaria emitindo um juízo do mundo exterior (Schapiro, 2010: 262). Já em I939, Clement Greenberg publicou o texto "Avantgarde and kitsch", na Partisan Review, manifestando-se também a favor da arte abstrata em detrimento do kitsch, visto por ele como manifestação artística que retratava a decadência da cultura burguesa. O abstracionismo, para esse crítico, seria a arte de vanguarda por excelência e atuaria como salvaguarda da cultura.

Io De acordo com Arantes (I99I: 3I), "Ao contrário do que dera a entender em sua fala de estreia, agora lhe parecia possível uma síntese, embora precária, entre atualidade estética máxima e arte social. Com uma diferença: a reconciliação entre estas duas províncias da civilização contemporânea se daria menos no plano mais explícito dos temas do que no terreno dos procedimentos artísticos, onde, à sua maneira e com recursos próprios, a arte reinterpreta o mundo moderno, nele incluído o universo tipicamente capitalista da técnica".

I I Foram encontrados dois cartões-postais trocados por Pedrosa e Calder, em I945, na Calder Foundation, localizada em Nova York.

I2 No original: "Mindlin was very enthusiastic about my work and said that I must come to Brasil. So four years 
later, in I948, having made various shipments of my work to Henrique in Rio, Louisa and I set out for Brasil - but our route was very devious".

I3 No original: "One evening we went to a macumba, somewhere in the Rio countryside. There were women in white dancing around in a big circle. We got into it too. I danced with a colored lady. Some russian photographer took a picture of us and published it in Fon Fon, a Rio scandal sheet".

I4 Esse prédio servia de abrigo provisório para as mostras do Museu de Arte Moderna do Rio de Janeiro, que ainda não havia inaugurado, mas já possuía uma diretoria desde 1947. Além desse museu, o Instituto dos Arquitetos do Brasil também apoiou a exposição, assim como o Instituto Brasil-Estados Unidos (Ibeu).

I5 Após essa vinda ao Brasil, Calder retornou outras vezes. Em I959, passou aqui um mês, por ocasião de mostra individual com suas obras no Museu de Arte Moderna do Rio de Janeiro. A exposição faria parte da programação do Congresso Extraordinário da Associação Internacional de Críticos de Arte, organizada por Pedrosa e que teve como objetivo discutir a construção de Brasília. Calder visitou Brasília ainda antes da inauguração e foi convidado a projetar um móbile para a futura capital do país, projeto que não se concretizou: "In February I960, we returned to Rio, to really see what the carnival was like, and I flew out again to Brasilia, this time carrying a little model of what I wanted to do for this city. Niemayer took the model and was going to show it to the presidente and get his agreement. I have never heard from Niemayer, or of the object, since" (Calder, I977: 253).

I6 No original: "While he spoke, I sat in the front row to hear better, but as it was in Portuguese, I dozed off. Finally the press took a picture and woke me up for this purpose. But as Mario was on the far side of the stage, all eyes were turned toward him, except mine that looked straight into the camera".

I7 Em sua autobiografia, Calder afirma que não tinha muito o que dizer sobre a exposição, com exceção de um detalhe: "Except that they had a book for everybody to write in and 
there were some long dissertations in Portuguese on my art, including one given by Pedrosa" (Calder, I977: 201).

I8 Sobre as relações de amizade, Claudia Rezende (200I: 260) afirma que a igualdade não é necessariamente uma condição para esse tipo de vínculo. Em vez de afirmar o valor da igualdade para essas relações, ela destaca aquele da afinidade: "A ênfase na afinidade não anula a percepção de diferenças entre amigos, mas mostra que o valor recai sobre aquilo que os torna semelhantes". No caso da amizade entre Pedrosa e Calder, as semelhanças pareciam repousar na afinidade entre valores estéticos presentes no trabalho do artista e o projeto crítico de Pedrosa, na sua defesa da abstração.

I9 Calder também participou dessa exposição com cinco móbiles, todos oriundos de coleções locais.

20 Pedrosa, Mário. “Arte-reflexo”, irresponsabilidade do artista. Jornal do Brasil, Rio de Janeiro, 2I/Io/I959.

2I A psicologia da forma ou Gestalt é uma "teoria segundo a qual nosso campo perceptivo se organiza espontaneamente, sob a forma de conjuntos estruturados e significantes ('formas boas' ou gestalts fortes e plenas)" (Ginger, I995: I3). Cabe enfatizar que, embora tivesse travado conhecimento com a teoria da Gestalt no final dos anos I920, Pedrosa só vai sistematizar os ensinamentos adquiridos nessa época na década de I940, por ocasião da escrita de sua tese "Da natureza afetiva da forma na obra de arte".

\section{REFERÊNCIAS BIBLIOGRÁFICAS}

Arantes, Otília Beatriz. (I99I). Mário Pedrosa: itinerário crítico. São Paulo: Editora Página Aberta.

Benzaquen, Ricardo. (20I4). Um grão de sal: autenticidade, felicidade e relações de amizade na correspondência de Mário de Andrade com Carlos Drummond. História da Historiografia, n. I6, p. I74-285.

Calder, Alexander. (1977). An autobiography with pictures. New York: Pantheon.

Collins, Randall. (1998). The sociology of philosophies: a global theory of intellectual change. Cambridge/Massachusetts/ London: The Belknap Press of Harvard University Press. 
Formiga, Tarcila S. (20I4). À espera da hora plástica: o percurso de Mário Pedrosa na crítica de arte brasileira. Tese de Doutorado. PPGSA/Universidade Federal do Rio de Janeiro. Ginger, Serge. (I995). Gestalt: uma teoria do contato. São Paulo: Summus.

Karepovs, Dainis. (200I) Mário Pedrosa e a IV Internacional (I938-1940). In: Marques Neto, José Castilho (org.). Mário Pedrosa e o Brasil. São Paulo: Fundação Perseu Abramo, p. 99-гзо.

Muneratto, Bruno Gustavo. (20II). Os movimentos da sensibilidade: o diálogo entre Mário Pedrosa e Alexander Calder no projeto construtivo brasileiro. Dissertação de Mestrado. Universidade Estadual Paulista.

Ortega, Francisco. (2009). Para uma política da amizade: Arendt, Derrida, Foucault. Rio de Janeiro: Relume Dumará.

Pedrosa, Mário. (2007). Mundo, homem, arte em crise. São Paulo: Perspectiva.

Pedrosa, Mário. (2000). Modernidade cá e lá. São Paulo: Editora da Universidade de São Paulo.

Pedrosa, Mário. (1979) Da natureza afetiva da forma na obra de arte. In: Arte: forma e personalidade. São Paulo: Editora Kairós, p. I2-50.

Pedrosa, Mary. (I980). Dados cronológicos. In: Homenagem a Mário Pedrosa. Rio de Janeiro: Galeria Jean Boghici.

Rezende, Claudia Barcellos. (200I). Entre mundos: sobre amizade, igualdade e diferença. In: Velho, Gilberto \& Kuschnir, Karina (orgs.). Mediação, cultura e política. Rio de Janeiro: Aeroplano, p. 237-264.

Sant'anna, Sabrina. (2004). "Pecados da Heresia": trajetória do concretismo carioca. Dissertação de Mestrado. PPGSA/ Universidade Federal do Rio de Janeiro.

Schapiro, Meyer (20IO). A arte moderna: séculos XIX e XX. São Paulo: Editora da Universidade de São Paulo.

Silver, Allan. (I990). Friendship in commercial society: eighteenth-century social theory and modern sociology. American Journal of Sociology, 95/6, p. I474-I504.

Vasconcelos, Marcelo Ribeiro. (2012) Arte, socialismo e exílio. Formação e atuação de Mário Pedrosa de I930 a I950. Dis- 
sertação de Mestrado. PPGSA/Universidade Federal do Rio de Janeiro.

Villas Bôas, Glaucia (org.). (20I6). Um vermelho não é um vermelho: estudos sociológicos sobre as artes visuais. Rio de Janeiro: 7Letras.

Villas Bôas, Glaucia. (20I4). Concretismo. In: Barcinski, Fabiana (org.). Sobre arte brasileira. São Paulo: Martins Fontes, p. 264-293.

Villas Bôas, Glaucia. (2008). A estética da conversão. $\mathrm{O}$ ateliê do Engenho de Dentro e a arte concreta carioca (I946-I95I). Tempo Social, São Paulo, 20/2, p. I97-2I9.

Williams, Raymond. (I982). The Bloomsbury fraction. In: Problems in materialism and culture. London: Verso Editions. 


\section{PROJETOS AFETIVOS E ESTÉTICOS: OS VÍNCULOS ENTRE O CRÍTICO DE ARTE MÁRIO PEDROSA E O ARTISTA ALEXANDER CALDER \\ Resumo}

O objetivo do artigo é investigar como a relação entre o artista norte-americano Alexander Calder e o crítico de arte brasileiro Mário Pedrosa contribuiu para o surgimento do programa concretista carioca nos anos I940 e i950. Durante seu exílio nos Estados Unidos, Pedrosa teve a oportunidade de conhecer o artista, com quem acabou por estabelecer uma relação de amizade. Os desdobramentos dessa relação podem ser vistos nos artigos escritos pelo crítico a partir de I944, que evidenciam, por um lado, profunda reflexão sobre a obra do artista e, por outro, a construção de um vocabulário para analisar a arte moderna e de argumentos que seriam mobilizados para justificar o desenvolvimento da arte concreta em solo brasileiro. Dentro de um quadro mais amplo de debates entre figurativistas e abstracionistas, o contato de Pedrosa com as obras de Calder e a transformação do escultor em figura-chave para seu programa crítico são aqui entendidos como fatores importantes para as mudanças que se processaram no modernismo brasileiro a partir de meados do século XX.

\section{AFFECTIVE AND AESTHETIC PROJECTS: THE LINKS BETWEEN THE ART CRITIC MARIO PEDROSA AND THE ARTIST ALEXANDER CALDER}

\begin{abstract}
who became his friend. The consequences of this relationship can be seen in the articles written by the critic, which show, on one hand, a deep reflection on the artist's work, and, on the other, the construction of a vocabulary to analyse modern art and of arguments mobilized to justify the development of concrete art on Brazilian soil. In the context of debates between figurativists and abstractionists, Pedrosa's contact with Calder's works and the transformation of the sculptor into a key figure for his critical program are comprehended in this paper as important factors in the changes that occurred within Brazilian modernism from the mid-twentieth century on.
\end{abstract}

Palavras-chave Mário Pedrosa; Alexander Calder; concretismo; crítica de arte; artes plásticas.

\author{
Keywords \\ Mário Pedrosa; \\ Alexander Calder; \\ visual arts; \\ art critic; \\ concretism.
}

